\title{
Radio - wstrząśnięte, nie zmieszane? Komiks radiowy w obliczu koncepcji „Media Martini”
}

\begin{abstract}
Radio programmes that prevail in the contemporaty „mediasphere” are prone to hybridization. They easily cross artificial generic divisions and get the status of multidimensional entities that activate many senses of media users. It is possible because they loose the distinctive features of audio broadcasts. As a result, they can take various forms, travel across media platforms and be consumed any time, any place. These criteria are fulfilled by „radio comic” - a specific „generic coctail” that reconciliates contradictions according to the rules imposed by audiovisual type of culture. However, it brings new quality to the media landscape, since it gives both radio dramas and „stories with balloones” more universal life. Referring to the productions such as „Nietoty”, „Jan Kalata” and „The Intergalactic Nemesis”, this article discusses the issue of transmediality of modern radio broadcasts. It presents many faces of „radio-comic” that stems from a strong tendency for radio visualization.
\end{abstract}

\section{Keywords:}

gereric hybridization, radio drama, radio-comic, radio visualization, transmediality of broadcasts

1 Karolina Albińska, Katedra Dziennikarstwa i Komunikacji Społecznej, Wydział Filologiczny, Uniwersytet Łódzki, Polska, albinskakarolina@yahoo.com. 


\section{W STRONĘ STRATEGII MEDIA MARTINI}

Radio od pewnego czasu ulega transformacji, dzięki której stopniowo staje się czymś więcej niż transmisją przeistoczonych w fale elektromagnetyczne dźwięków przekształcanych w urządzeniach odbiorczych ponownie w przekaz dźwiękowy. Obecnie ma różne oblicza. Jest nim materiał emitowany za sprawą klasycznych urządzeń radiowych, ale też różne odmiany „nowego radia 2.0”, w tym: „radio naziemne (DAB, DRM, IBOC), telewizja naziemna (DVB-T), ruchome multimedia (DVB-H, DMB), radio satelitarne oraz systemy pozaradiowe i telewizyjne (radio satelitarne, radio internetowe - Web streaming i podcasting), a także zaawansowane systemy telefonii komórkowej, sieci szerokiego dostępu oraz różne systemy hybrydowe” (Jędrzejewski, 2007, s. 168). Stworzenie stabilnej definicji tego medium jest więc niesłychanie trudne, tym bardziej, że sposoby dystrybucji przekazu radiowego często pozwalają na wplecenie w jego tkankę również treści zwizualizowanych. Radio jest zatem de facto multitworzywowe i multiplatformowe.

Podziały między przekazami, które określić można mianem radiowych, a pozostałymi produkcjami i mediami stały się dziś płynne, a granice niegdyś dość wyraźnie odseparowujące od siebie środki masowego przekazu, zacierają się zarówno w odniesieniu do samych przekaźników i kodów znakowo-estetycznych, którymi się one posługują, jak i emitowanych treści. Już od lat osiemdziesiątych XX w. kwestionuje się bowiem istnienie ostrych linii demarkacyjnych między elektronicznymi środkami komunikowania. Coraz chętniej przyjmuje się również założenia, że przyszło nam żyć w erze konwergencji mediów, która rzutuje na ich wymiar technologiczny, ekonomiczny oraz społeczno-kulturowy, w tym zawartość przekazów i zachowania medialne konsumentów (Kopecka-Piech, 2011). Nadawcy są świadomi, że z uwagi na upodobania odbiorców istnieje potrzeba tworzenia oferty, jaka rozszerza emisję programów na nowe przestrzenie w taki sposób, by uatrakcyjnić same audycje i ich prowadzących, ale także rozszerzyć je poza ramówkę (Berry, 2013). Snują więc tzw. opowieści transmedialne - przekaz, który: „rozwija się na różnych platformach medialnych, a każdy tekst stanowi wyróżniającą się i ważną część całości. W idealnej formie opowiadania transmedialnego każde medium porusza się w sferze, w której jest najlepsze [...], tak aby historia mogła zostać wprowadzona w filmie, a rozwinięta przez telewizję, powieści i komiksy” (Jenkins, 2007, s. 95-96). Ten sposób budowania rzeczywistości medialnej praktykuje z sukcesem np. koncern BBC, który hołduje zasadzie „Listen, Watch, Share”, zachęcając do tradycyjnego odbioru programów radiowych, ale też dzielenia się materiałami wizualnymi, które audycjom towarzyszą, nawet jeśli obrazowość pozostaje zwykle tylko dodatkiem do przekazu czysto dźwiękowego. 
Pionierem tej koncepcji był prawdopodobnie Mark Thompson, który w 2006 r. posłużył się terminem „Media Martini”, by przedstawiać swój plan rozwoju dla wspomnianego publicznego nadawcy, nazwany „Creative Future”. Tłumacząc założenia kryjące się w tym metaforycznym haśle, dyrektor generalny podkreślał, że: „[...] oznacza to, że musimy przyjąć zupełnie nowe podejście do rozwoju, komisjonowania i produkcji realizowanych przez BBC. Od teraz, kiedy tylko się da, musimy myśleć międzyplatformowo, między TV, radiem i Internetem dla publiczności w domu i w drodze” (Thompson, 2006, s. 2-3). Zapoczątkowując ten „nowy rozdział” uświadamiał sobie, że tradycyjne radioodbiorniki będą jeszcze przez lata podstawowym sposobem upowszechniania audycji radiowych, ale wiedział również, że wspomniane sposoby dystrybucji wstrząsną krajobrazem medialnym, dodając przekazom bezobrazowym wizualnego wymiaru. Rewolucja ta zatem ,ani nie umniejszy wpływu dźwięku, ani w sposób istotny nie zmieni natury tego [radiowego] medium” (Berry, 2013, s. 171). Doprowadzi natomiast do: „transformacji gatunków w wyniku zbieżności starszych elementów w nowych rozwiązaniach” (Kopecka-Piech, 2011, s. 21), bo współcześnie: „nowość, a raczej jej wrażenie, może powstać w wyniku manipulacji przedmiotami już istniejącymi, łączeniem ich w nowe struktury i figuracje, odkrywające nieznane cechy oraz potencje [...]” (Bauer, 2009, s. 147). Ciekawym wyrazem wcielenia w życie tego typu strategii stał się tzw. komiks radiowy.

\section{KOMIKS RADIOWY - PRÓBA DEFINICJI}

Na próżno szukać hasła „komiks radiowy” w słownikach ogólnotematycznych, i kompendiach wiedzy z zakresu medioznawstwa. Znawcy tematyki radiowej, tworząc typologie gatunków, również pomijają tę formę przekazu milczeniem. Nie powinno to budzić zdziwienia, bo „radio-komiks” „z trudem można opisać jako jasno zdefiniowany „gatunek radiowy” w tradycyjnym znaczeniu” (Hepp, 2006, s. 197). Jest raczej otwartym „produktem programowym”. Ponadto szybko zachodzące zmiany środowiska medialnego powodują, że z opóźnieniem odbywa się aktualizacja „bazy” bytów medialnych, szczególnie tych najbardziej problematycznych tj. gatunków hybrydowych, czy też hybryd gatunkowych, które definiuje się jako „wypowiedź łączącą w jedną całość dwa (lub więcej gatunki o całkowicie odmiennych cechach definicyjnych (wyznacznikowych), zwłaszcza odmiennych funkcjach; także - scalającą gatunki należące do odmiennych systemów znakowych” (Fras, 2007, s. 22). Tymczasem to hybrydowość gatunkową uznać należy za 
normę, nie odstępstwo od reguł rządzących obecnie światem prasy, radia, telewizji oraz Internetu (Bauer, 2009).

Nieobecność tej kategorii w typologii radiowej nie oznacza jednak braku potrzeby jej wprowadzenia. Taki postulat wysuwa Łastowiecki (2018, s. 1) słowami: „Zastanawiam się coraz bardziej, czy za kilka, kilkanaście lat, w encyklopediach i podręcznikach medioznawczych nie pojawi się definicja komiksu radiowego [...] Powrót do formuły teatru naturalnego, a także coraz większa hybrydyczność może za kilka lat wymagać zmian definicyjnych. Niestety, radio jest taką sferą, za którą trudno nadążyć słownikom i «handbookom»”. Marzenie o wprowadzeniu i upowszechnieniu wspomnianego terminu spełnia się jednak już dziś, bo nazwą „komiks radiowy”, „Hörcomic”, „radio comic”, „audio-comic” lub „komiks dźwiękowy” zaczynają posługiwać się praktycy radiowi oraz naukowcy, którzy próbują możliwie najtrafniej scharakteryzować różne zjawiska medialne. Terminy te pojawią się wprawdzie jeszcze na prawach incydentu, ale w bardzo różnych kontekstach. Można zatem pokusić się o naszkicowanie ogólnego obrazu, czym w istocie jest nazwany w ten sposób mix, który, wnioskując na podstawie nomenklatury, ma być hybrydycznym połączeniem bazujących na kodzie wizualnym form komiksowych oraz radiowych przekazów audialnych.

Najbardziej ogólnego zdefiniowania terminu „komiks radiowy” podjął się Hepp (2006, s. 190), który anonsował w swoim artykule: „będę zajmować się komedią radiową w znaczeniu akustycznych ekwiwalentów zeszytów komiksowych lub pasków komiksowych”. Rozwijając swoje poglądy dookreślał jednak, że pod etykietą „radio-comic” kryją się poszczególne części niektórych programów w strumieniu radiowym, które uznać można za satyryczne fragmenty rozrywkowe. Każdy osiąga maksymalną długości 120 sekund i na wzór drukowanych komiksów, bazuje na przesadzie i wyolbrzymieniach. Autor ten zarezerwował więc to określenie dla prezenterskich wejść antenowych o zabarwieniu humorystycznym, które pełnią funkcję łączników. „Komiksowość” pojmował zaś w sposób metaforyczny, utożsamiając obrazowość owych przekazów z uruchamianiem wyobraźni odbiorców.

Równie dźwiękowym torem rozumowania podąża Małgorzata Żerwe, choć swoje rozważania o „komiksie radiowym” przenosi na grunt „międzygatunkowych” form artystycznych. W taki dość zagmatwany sposób wyjaśnia ona, dlaczego jej produkcji „Kafka Unchained”, zrealizowanej w 2014 r. przez australijską stację ABC, zdecydowano się nadać podtytuł „Hörcomic”:

„Mieliśmy dość materiału i pomysłów na to, by skonstruować audycję radiową. Naszym zamiarem było zrobienie komiksu radiowego, ponieważ lubimy różne wyzwania i pracować w bardzo różnych konwencjach [...] No to tak 
jak rysownik - są jakieś nieoczekiwane zwroty, jest przybliżenie czegoś [...] W naszej audycji pojawia się [...] legenda amerykańskiego undergroundu, Robert Crumb [...] ilustratorka francuska Chantal Montellier, która zrobiła rysunki do „Procesu” i „Zamek” - wiadomo, musiał to zrobić Czech, Jaromír 99 [Švejdík], który też jest punkrockowcem. W naszej audycji spotykają się też [...] kafkolog z Senegalu, który jest nagrany przez telefon [...] Franz Kafka, którego spotkaliśmy w Salzburgu [...] To wszystko jest właśnie takie komiksowe, takie pełne zaskoczeń [...] Naszą audycję buduje też muzyka [...] „Kafka Band”, który śpiewa piosenki oparte na tekstach Kafki [...] To są aktorzy, którzy czytają. To są te słuchowiskowe elementy [...] Kafka, który pisze po niemiecku, oczywiście wszyscy autorzy, którzy mówią w swoich rodzimych językach [...] No i wymyśliliśmy właśnie tych parę narratorów, którzy dialogują też ze sobą, dialogują z naszymi bohaterami, z samym Kafką. No musi też ktoś przeczytać teksty Kafki, bo tekstów Kafki też tam jest sporo [...] Artystyczna forma to nie już tylko używanie środków typu efekty [...] artystyczne to jest wtedy, gdy naprawdę pobudza naszą wyobraźnię i jest poza codziennym stosowaniem środków radiowych” (Grand PiK, 2015, s. 1).

Ten eklektyczny zlepek elementów rzeczywistych i fikcyjnych sprawia, że „komiks-radiowy” „Kafka Unchained” bywał klasyfikowany przy okazji konkursów także jako feature. Takiego określenia używał zresztą drugi z jego twórców - Mairowitz - który tym samym utrzymywał, że jest on specyficzną kompilacją dwóch dźwiękowych form gatunkowych - reportażu i słuchowiska („Kafka Unchained”, Hörcomic von Malgorzata Zerwe, 2014).

Najbardziej szczegółową definicję „komiksu radiowego” ukuł Łastowiecki (2015), który utożsamia go wyłącznie ze słuchowiskiem radiowym, a swoje poglądy przedstawił zachowując dwukierunkowość myślenia: „Stajemy się słuchaczami migawkowymi, zdolnymi w każdej chwili do zrzucenia słuchawek w połowie wypowiadanego w nich zdania. Stajemy się uczestnikami komiksu pod radiowym napięciem [...] O tej formie wspominał już kilkakrotnie Krzysztof Sielicki, kierownik literacki Teatru Polskiego Radia. Zapewne wpływ na to miały obserwacje rozgłośni zagranicznych, gdzie słuchowisko ewoluuje już w wielu kierunkach [...] Projekt komiksu radiowego rozumiem dwutorowo. Po pierwsze jako mariaż tekstu obrazkowego i dźwięku [...] Po drugie - formuła komiksowa zaczyna funkcjonować jako odpowiednik dawnych, epickich wręcz przeniesień literatury w eter. Czasy się zmieniają, radio mówi coraz szybciej. W info-rozrywkowym natłoku pojawiła się potrzeba realizowania dźwiękowych adaptacji, które nie będą 
recytacją dużych partii lektur [...] Środkiem do połączenia misji radia publicznego i szacunku dla coraz krótszego czasu słuchaczy staje się właśnie komiksowość, zdolna do przekształceń i przekrzywień” (Łastowiecki, 2015, s. 1-2). W cytowanym felietonie autor licznie przywołuje dzieła, które są ucieleśnieniem różnych strategii tworzenia „komiksu radiowego” (Łastowiecki, 2015, s. 1-2):

\begin{tabular}{|c|c|}
\hline \multicolumn{2}{|c|}{ Słuchowiskowy „komiks radiowy” } \\
\hline wizualne & audialne \\
\hline & $\begin{array}{l}\text { W adaptacjach - komiksowość „signum } \\
\text { temporis”. } \\
\text { W tekstach oryginalnych - komiksowość } \\
\text { „raczkuje” i często jest „nieuświadomiona”. }\end{array}$ \\
\hline $\begin{array}{l}\text { „Pensjonat” - Darek Błaszczyk } \\
\text { - graficzny anons internetowy przed pre- } \\
\text { mierą dźwiękową - wprowadzał w atmosferę } \\
\text { audycji, dzięki niemu przekaz stawał się „wy- } \\
\text { darzeniem i nie ginął w przestrzeni ramówki”. }\end{array}$ & $\begin{array}{l}\text { Szekspirowska adaptacja dzieła o królu Ry- } \\
\text { szardzie - } 52 \text { min.; „Beniowski” - } 44 \text { min. } \\
\text { - skrótowość, esencjonalność }\end{array}$ \\
\hline $\begin{array}{l}\text { Słuchowiska na podstawie powieści Joanny } \\
\text { Chmielewskiej - fotokasty - zdjęcia ze } \\
\text { studia radiowego } \\
\text { • felietonista nie jest zwolennikiem tej formy } \\
\text { wizualizacji }\end{array}$ & $\begin{array}{l}\text { „Król mrówek” Zbigniewa Herberta - Tomasz } \\
\text { Man } \\
\text { „wyobraźnia rysowana” } \\
\text { - akcentowany plastycznymi efektami } \\
\text { dźwiękowymi tekst nie służy opisowi, ale } \\
\text { ma cechy „dymkowe” - można byłoby go } \\
\text { rozpisać w taki sposób }\end{array}$ \\
\hline $\begin{array}{l}\text { „Śmierć w Wenecji” Thomasa Manna w for- } \\
\text { mule „rozszczepionej” narracji Tomasza Mana } \\
\text { - archiwalne filmy z Wenecji podczas festi- } \\
\text { walowego pokazu }\end{array}$ & $\begin{array}{l}\text { „Morderstwo w hotelu Santa Caterina” Irene- } \\
\text { usza Iredyńskiego - Marcin Hycnar } \\
\text { - w podtytule „radiowy komiks krymi- } \\
\text { nalny” } \\
\text { - dźwięki silnie budują klimat i przestrzeń } \\
\text { - umowność postaci, bez głębi psycholo- } \\
\text { gicznej } \\
\text { - aktorzy - „ołówkowe rysy, ich wypo- } \\
\text { wiedzi zatrzymane jak twarze na arkuszu } \\
\text { rysownika” }\end{array}$ \\
\hline $\begin{array}{l}\text { „Nietoty” - Sebastian Majewski - Jan Kalata } \\
\text { - „komiks” o tym samym tytule Jakuba } \\
\text { Woynarowskiego }\end{array}$ & $\begin{array}{l}\text { „Rekonstrukcja poety” Zbigniewa Herberta - } \\
\text { Andrzej Zakrzewski, Eugeniusz Rudnik } \\
\text { - zakodowanie niedopowiedzenia Gustawa } \\
\text { Holoubka i urwanie porykiwania żubra - } \\
\text { jak w „dymku” } \\
\text { • felietonista postuluje rozwinięcie plastyczne } \\
\text { tego przekazu }\end{array}$ \\
\hline
\end{tabular}

Wykaz ten z pewnością nie jest wyczerpujący, bo „komiksowość” słuchowisk objawia się zarówno poprzez ich miniaturyzację, która niekiedy przeobraża je w 3-5 minutowe przekazy serialowe wtłoczone w większe struktury megaga- 
tunkowe, np. morning show (Crook, 2015, s. 1-3), wszelkiego rodzaju zabawę formą, w tym remake, w który wkomponowuje się fragmenty słuchowiskowego pierwowzoru, jak i zobrazowany dźwiękowy kontent. Daje się go opisać przy użyciu sześciu kategorii (Berry, 2013, s. 175):

\begin{tabular}{|c|c|c|}
\hline \multicolumn{3}{|c|}{ Różne formy wizualizacji radia } \\
\hline \multicolumn{3}{|c|}{ Emisja „na żywo” } \\
\hline $\begin{array}{l}\text { Materiały bazujące na } \\
\text { użyciu kamery }\end{array}$ & $\begin{array}{l}\text { Materiały „wzbogacające” } \\
\text { odbiór o wymiar wizualny }\end{array}$ & $\begin{array}{l}\text { Materiały „potęgujące” } \\
\text { doświadczenie obrazowości }\end{array}$ \\
\hline $\begin{array}{l}\text { Live streaming - obraz ze } \\
\text { studia dzięki zastosowaniu } \\
\text { kamer }\end{array}$ & $\begin{array}{l}\text { Wizualne treści z mediów } \\
\text { społecznościowych nadsyłane } \\
\text { przez słuchaczy, które uzupeł- } \\
\text { niają interakcję na żywo }\end{array}$ & $\begin{array}{l}\text { Dodatkowe dane wizualne na } \\
\text { ekranie w postaci np. grafik, } \\
\text { tekstu, wykresów i map, które } \\
\text { towarzyszą audycji na żywo }\end{array}$ \\
\hline \multicolumn{3}{|c|}{ Emisja „na życzenie” } \\
\hline $\begin{array}{l}\text { Materiały bazujące na } \\
\text { zastosowaniu kamery }\end{array}$ & $\begin{array}{l}\text { Materiały „wzbogacające” } \\
\text { odbiór o wymiar wizualny }\end{array}$ & $\begin{array}{l}\text { Materiały „potęgujące” } \\
\text { doświadczenie obrazowości }\end{array}$ \\
\hline $\begin{array}{l}\text { Elementy zwizualizowane są } \\
\text { nagrane w studiu radiowym } \\
\text { w trakcie emisji programu, ale } \\
\text { są konsumowane już po jego } \\
\text { premierze }\end{array}$ & $\begin{array}{l}\text { Użycie zdjęć lub nagrań au- } \\
\text { dio-wideo, które dodają nową } \\
\text { jakość, dopowiadając nowe } \\
\text { treści do tego, co zostało } \\
\text { wcześniej nadane }\end{array}$ & $\begin{array}{l}\text { Kontent wizualny, który po- } \\
\text { budza wyobraźnię odbiorców } \\
\text { przed lub po czasie premiero- } \\
\text { wego nadawania programu }\end{array}$ \\
\hline
\end{tabular}

Twórcy słuchowisk radiowych coraz chętniej sięgają po te techniki wizualizacji radia. W efekcie powstają zobrazowane słuchowiskowe przekazy na żywo, np. „Wesele” Wyspiańskiego zrealizowane przez Radio Kraków, ale także produkcje uwzględniające odbiór niesynchroniczny, bazujące na dodatku fotograficzno-filmowym (tzw. fotofilmy, np. niektóre realizacje z serii „The City Speaks”), a nawet całej „ścieżce wizualnej”, tworzonej przy użyciu technik animacji filmowej z wykorzystaniem marionetek teatralnych (np. „Dickens in London”).W kontekście niniejszego wywodu najciekawsze wydają się jednak te współczesne realizacje, które ściśle splatają słuchowiska radiowe z tworzywem komiksowym.

\section{WSPÓŁCZESNY ŻYWOT SŁUCHOWISKOWEGO KOMIKSU}

Związek komiksów i słuchowisk radiowych ma długą tradycję, która sięga lat 40 i 50 XX w. Już wówczas tworzono „Teatr Wyobraźni”, zapożyczając jego bohaterów z opowieści z dymkiem (tzn. nurt amerykańskich słuchowisk superbohaterskich). Czasami zależność ta miała także kierunek odwrotny. Wówczas postacie z dzieł audialnych wtórnie dostawały obrazkowych rysów na kartach 
zeszytów komiksowych (Zrodzeni poza komiksem, 2015). Dziś ten wzajemny wpływ bywa jeszcze silniejszy i bardziej złożony, a jego pokłosiem są bardzo ciekawe eksperymenty artystyczne.

Jednym z nich jest „radiowy komiks” Jakuba Woynarowskiego, który stworzono na bazie słuchowiska „Nietoty” Sebastiana Majewskiego w reżyserii Jana Kalaty. Opowieść wizualna w komiksowej odsłonie była w tym przypadku odzwierciedleniem w rysunku audycji nagrodzonej na festiwalu Dwa Teatry w 2014 r. Komiks ów publikowano na stronach internetowych Radia Kraków w dniach od 4 do 13 grudnia. Premiera samej sztuki radiowej odbyła się trzy dni później. O tej zaplanowanej, przesuniętej w czasie strategii emisyjnej tak opowiadał Marcin Pulit: „Poszliśmy o krok dalej [...] Przy pierwszej realizacji Jana Kalaty w Radiu Kraków - słuchowisku „Dumanowski” - komiks Macieja Sieńczyka stworzony został po premierze i towarzyszył wydaniu płytowemu „Dumowskiego”. Tym razem to komiks poprzedzał więc słuchowisko” (W radiowym komiksie, 2013).

Zobrazowana historia, osnuta na kanwie wydarzeń związanych z tzw. Hańbą Podhala, miała prawdopodobnie zaostrzyć apetyt odbiorców na doznania słuchowe. Niedopowiedzenie kryjące się w opowieści audio - surrealistycznej i po części fikcyjnej, bo inspirowanej jedynie rzeczywistymi wydarzeniami - starano się w konsekwencji przełożyć także na niedosłowność prezentacji wizualnej utrzymanej w komiksowej konwencji. Świadczy o tym następująca wypowiedź:

„Tekst słuchowiska jest bardzo metaforyczny, posługuje się abstrakcyjnymi figurami, językiem symboli. Starałem się wykorzystać te symbole na poziomie wizualnym i odnieść się do ikonosfery związanej z jednej strony z Podhalem, z drugiej z nazizmem. Konkretna historyczna sytuacja została wyniesiona na poziom uniwersalny i tak też będę chciał podkreślić to w swoim komiksie. [...] Myślałem żeby podejść do tego nietypowo, stworzyć komiks abstrakcyjny, operujący na poziomie symboli [...] Formuły wizualne, które spotykamy w świecie nauki wydają mi się tu atrakcyjne, żeby były kontrapunktem dla treści. Taka forma trochę diagramu, infografiki - obrazy zaczerpnięte z języka naukowej wizualizacji wydają mi się tu interesujące [...] Będę kontynuował tę linię kolorystyczną, którą wybrałem w tworzeniu plakatu. Tu jest ta triada kolorystyczna i tak też oznaczę trójkę głównych bohaterów. Przez to staną się bardziej rozpoznawalni i ta wymiana między nimi będzie rozgrywać się nie tylko na poziomie formy, ale i koloru” (Zapis rozmowy, 2013, s. 2-3).

W rezultacie w obrazkowej interpretacji kontrowersyjnego epizodu z czasów II wojny światowej odbiorca nie zobaczył twarzy postaci, ani naturalistycznych 
krajobrazów. Wyłoniły się z niej natomiast różnie warianty wiele mówiących znaków, takich jak swastyka, czerwona gwiazda oraz symbol Polski walczącej. Troje bohaterów - Witalis Wieder, Włodzimierz Ilicz Lenin oraz Wolna Elektroda istnieli jedynie w graficznej postaci, która nadawała wizualizacji słuchowiska uniwersalnego wydźwięku za pomocą geometryczno-abstrakcyjnych środków. W całość wpleciono jednak również na wskroś współczesny kod graficzny wpisaną w przestrzeń Internetu symbolikę typową dla Google Maps, Facebooka lub programu Word.

Z tego względu - zdaniem Rajnerowicza (2015) - obrazkowa wersja tego słuchowiska „nie spełnia kryteriów formalnych komiksu radiowego”. Jest raczej „monumentalną łamigłówką”, tworzącą „fascynujący język współczesnych hieroglifów”, który stara się zredukować podział między tekstem i ilustracją. Przypomina tym samym „,postmodernistyczną parodię czytanki dla dzieci, instrukcji obsługi, elementarza, kolekcji rebusów bez rozwiązania czy może przegiętej dizajnersko księgi znaku z historycznym wątkiem narracyjnym” (Rajnerowicz, 2015, s. 3). Jest raczej „wizualnym suplementem”, a nie komiksem w klasycznym znaczeniu. Tym bardziej że oprócz swojej czysto radiowej postaci i zwizualizowanej elektronicznej publikacji na stronach internetowych słuchowisko „Nietoty” występuje również jako wydawnictwo papierowe z płytą CD. „Radiowy komiks” jest więc w tym przypadku wartością dodana i to niesamodzielną. Niemożliwe wydaje się bowiem oglądanie go ze zrozumieniem bez wcześniejszej znajomości jego dźwiękowego ekwiwalentu ani konsumowanie go synchronicznie z jego czysto audialną wersją.

Choć dosłowna „komiksowość” tego dzieła w jego graficznej odsłonie zostaje poddana w wątpliwość, bo w dzisiejszych czasach ilustracje z dymkiem muszą wykazywać się kompletnością i autonomią, by uchodzić za osobną formę artystyczną, a nie tylko dopełniać wątek narracyjny (Rajnerowicz, 2015), nie można zaprzeczyć, że wspomniane rysunki trafnie oddają „komiksowe” przerysowanie i eksperymentalny charakter słuchowiskowego scenariusza oraz jego dźwiękowej realizacji, którą - ze względu na dość abstrakcyjną fabułę - trudno byłoby prawdopodobnie zobrazować w mniej awangardowy sposób.

Zwizualizować „Teatr wyobraźni” przy użyciu bardziej konwencjonalnych technik komiksowych starali się z kolei twórcy słuchowiskowego serialu „Jan Kalata”, który miał swoją premierę w 2016 r. w szczecińskim kinie Helios. W jej trakcie aktorzy odczytywali dla kilkuset zgromadzonych na sali osób radiowy scenariusz opowiadający historię życia legendarnego kuriera i emisariusza władz Polskiego Państwa Podziemnego Jana Kozielewskiego, znanego jako Jan Karski (pseudonim). W rolę głównego bohatera sztuki radiowej, wyreżyserowanej przez Krzysztofa Czeczota, wcielił się Jakub Gierszał. Prezentację w formie odczytu na 
żywo, nawiązującą do tradycji „,widowisk słuchowych” z ery raczkowania radiofonii, więc wzbogaconą poniekąd o aspekt wizualny, zwiastowano również w formie obrazowej - „filmowym” trajlerem z napisami w języku polskim. Trzeba było się nimi posłużyć, gdyż obsada złożona z ponad 40 topowych aktorów posługiwała się w trakcie realizacji dźwiękowej słuchowiska językiem polskim, niemieckim, angielskim, rosyjskim, słowackim, francuskim oraz włoskim, chcąc możliwie najtrafniej oddać realia danej epoki i różne miejsca rozgrywania akcji. Ścieżkę dźwiękową w języku polskim czytał w kinie, ale też w wersji emitowanej później na falach radiowego eteru, Janusz Szydłowski (Jan Karski, 2016). Trzynastoodcinkowy przekaz audio o całkowitej długości 5 godzin i 37 min., nad którym prace trwały od wiosny 2015 r., był następnie nadawany na antenie Radia Szczecin od 11 stycznia 2016 r. W każdy dzień roboczy słuchacze mogli zatem uczestniczyć w radiowym „Teatrze Wyobraźni”, a poszczególne epizody rozbrzmiewały po godz. 9:00 i 14:00 i trwały około 5 min. (Łukaszek, 2016). Owa skrótowość serwowanych użytkownikom radioodbiorników odcinków oddawała adekwatnie „komiksowość” postrzeganą przez pryzmat dźwiękowy, o której wspomniano już w niniejszym artykule.

Do kategorii „komiks radiowy” tę słuchowiskową opowieść zakwalifikować można jednak przede wszystkim na podstawie jej innych zwizualizowanych wersji. Już debiutanckie wykonanie w sali kinowej odbiorcy mogli „podglądać” w Internecie na stronie www.radioszczecin.pl. Z czasem uruchomiono również specjalną platformę internetową http://jankarski.edu.pl. Dopiero ona pozwoliła na wzbogacenie fragmentów słuchowiska o komiksowe ilustracje. Z założenia miała pełnić funkcję edukacyjną, ułatwiającą prowadzenie interaktywnych zajęć szkolnych na temat wydarzeń poruszanych w słuchowiskowym scenariuszu. Obranie takiego adresata na jego głównego odbiorcę nie było bez znaczenia, co podkreślał reżyser słowami: „Za tym idzie szereg dodatkowych zdarzeń. Będzie strona internetowa poświęcona Janowi Karskiemu, co ważne - w komiksie, tak żeby dostęp do niej był atrakcyjny dla młodych ludzi” (Łukaszek, 2015).

Chronologicznie zaprezentowany audialny życiorys, od wybuchu wojny do wizyty w Białym Domu i relacji zdanej przez Karskiego Rooseveltowi na temat tragicznego losu ludności żydowskiej w czasach okupacji nazistowskiej, uzupełniono finalnie w Internecie barwnymi ilustracjami. Utrzymanymi w komiksowej konwencji, choć pozbawionymi charakterystycznych dla stylistyki komiksu wypowiedzi słownych w „chmurkach”, bo te zastąpiła słuchowiskowa „ścieżka dźwiękowa”. Prezentowano je odbiorcom stopniowo w formie ruchomej wizualizacji. Oglądający miał w konsekwencji wrażenie, jakby na jeden komiksowy obrazek nakładano kolejne przeźrocza, uzupełniając w ten sposób przekaz wizualny o coraz 
więcej rysunkowych detali. Każda „piętrowa” ilustracja przypisana była osobnemu odcinkowi audialnemu. Taka Internetowa prezentacja przepleciona była również planszami z tekstem wyświetlanym na tle ruchomych wizerunków chmur. Przerywniki te stanowiły dodatkowe uzupełnienie audialno-komiksowego materiału. Pozwalały jednak całości zachować status zobrazowanego słuchowiska - prowokującego do uruchamiania wyobraźni, bo wciąż nie w pełni „dopowiedzianego” pod względem wizualnym.

Jeszcze bardziej krętą drogę do stworzenia „komiksu radiowego” przebyli kreatorzy „The Intergalactic Nemesis” - trylogii science fiction o inwazji „Zygonians”, nawiązującej do konwencji zapoczątkowanej przez słynną „Wojnę Światów”. Punktem wyjścia do stworzenia historii o perypetiach dociekliwej reporterki (Molly Sloan), jej asystenta (Timmy’ego Mendeza), dzielnego bibliotekarza (Bena Willcotta) i podstępnego hipnotyzera, która z czasem rozrosła się do transmedialnego przekazu, było stworzenie scenariusza słuchowiska radiowego w 1996 r.² (The Intergalactic Nemesis. Study Guide, 2016). Początkowo prezentowano je w niedziele w formie teatralnego przedstawienia ${ }^{3}$ w Little City Espresso Bar \& Cafe w Austin w Teksasie. Składało się z dwóch piętnastominutowych epizodów pisanych z częstotliwością co siedem dni i wystawianych przez pięć tygodni. Z czasem skrypt ten stał się „,retro nagraniem”, zarejestrowanym na starym odtwarzaczu przez twórcę dźwiękowych efektów specjalnych - Buzza Morana. Tylko na tyle pozwalał bowiem wówczas niewielki budżet. Rok później słuchowisko w jego czysto dźwiękowej postaci wyemitowała lokalna radiostacja. Wraz z wejściem w nowe millenium producent i reżyser, Jason Neulander, unowocześnił przekaz, kolejny raz przekształcając go z pomocą współpracowników w formę przedstawienia „na żywo”, które w latach 2000-2001 wystawiano w State Theatre w Austin. Powstał wtedy również sequel - „Return of the Intergalactic Nemesis”. Obie części odgrywano w salach teatralnych i kinowych. W 2002 r. pierwsza z opowieści przeżyła drugą radiową młodość dzięki stacji KUT, by w 2005 r. po raz kolejny trafić na sceniczne deski (Herrera, 2015).

Najważniejszy przełom wizualizacyjny nastąpił dopiero w 2009 r., gdy trwały już prace nad papierową wersją tej opowieści. Planowano ją sprzedawać w trakcie teatralnych odtworzeń (Otten, 2011) i ostatecznie przybrała formę serii komiksowej złożonej z siedmiu zeszytów. Wówczas Jason Neulander wpadł na pomysł, by połączyć konwencję słuchowiskową i teatralną w spójną, nowatorską jedność,

2 Autorzy: Ray Patrick Colgan, Lisa D’Amour, Julia Edwards, Jessica Reisman.

3 Adaptacji dokonali Jason Neulander i Chad Nichols. 
wzbogacając ją o walor rysunkowy. Zdaniem reżysera „zabawnie było łączyć dwie stare formy, które oryginalnie stworzono w latach 30. - słuchowiska i komiksy” (Adler, 2016). Podobne odczucia miał Buzz Moran, który dopowiadał: „Sądzę, że lubimy fakt, iż wszystkie indywidualne elementy są trochę archaiczne [...] Wszystkie te proste elementy razem zmieniają się w coś złożonego i innego” (Ross, 2014, s. 2).

Efekt tych zabiegów pokazano audytorium po ośmiu miesiącach (The Intergalactic Nemesis. Study Guide, 2016). Stworzenie tego rodzaju kompilacji wymusiła zaś sytuacja, bo twórców - załamanych wycofaniem się inwestora poproszono dość nieoczekiwanie o wystawienie wspomnianego radiowego słuchowiska w Long Center for the Performing Arts. Artystom mającym wystąpić przed widownią liczącą 2400 osób, projekt, w którym udział brało tylko 6 ludzi, wydawał się zbyt „ubogi”. Postanowili więc wzbogacić warstwę dźwiękową słuchowiskowego spektaklu o komiksowe ilustracje. Po latach tak wspomina tę chwilę Neulander: „właśnie miałem odrzucić ofertę, kiedy jako przebłysk pojawiło mi się wyobrażenie stronicy z zeszytu komiksowego na ekranie wielkości łuku proscenium, które stworzy rodzaj przedstawienia mogącego wypełnić tak dużą przestrzeń” (Copley, 2014, s. 1). Wkrótce tę wizję przekuto w rzeczywistość. Połączono pierwsze dwie strony komiksu, które w owym czasie były już gotowe, z materiałem audialnym, tworząc na laptopie trwającą 1 min. i 9 sek. mieszankę różnych pod względem tworzywowym przekazów medialnych i jednocześnie modyfikując pierwotny słuchowiskowy scenariusz, by usunąć z niego przydługie partie opisowe. Innowacyjny pomysł stał się w ostatecznym rozrachunku: „interaktywną koncepcją łączącą wizualny dreszczyk towarzyszący klasycznym zeszytom komiksowym ze starą szkołą audialnej immersji, którą dawały radiowe słuchowiska i z postmodernistyczną dramaturgią aktorów recytujących zawartość dymków dialogowych” (Eck, 2013, s. 1). Przedsięwzięcie okrzyknięto zaś - unikalną w skali świata - hybrydą (Hampel, 2012), której przyklejono etykietę „Live Action Graphic Novel”.

Zdaniem Briana Herrery (2015) nazewnictwo to nie w pełni oddaje jednak istotę tego „multimedialnego eventu”, czy też - mówiąc słowami samych jego twórców - „independently-produced transmedia multiverse”. Tak naprawdę jest to bowiem „transmedialne przedstawienie na żywo, które opiera się prostym opisom, nawet wtedy, gdy dąży do szerokiego, powszechnego oddziaływania” (Herrera, 2015, s. 1) i pełni rolę rodzinnego show o kilku poziomach znaczeniowych. To właśnie dodatek komiksowych ilustracji do słuchowiska prezentowanego w teatrze sprawia, że staje się ono „komiksem radiowym”. Jest bardziej współczesne i interesujące. Jest „oszałamiającym i nostalgicznym spojrzeniem wstecz na dni świetności sztuk 
radiowych, ale lekko wykoślawionym” (The Intergalactic Nemesis. Target Earth, 2015, s. 1).

Aktorom - Rachel Landon, Brockowi Englandowi oraz Christopherowi Lee Gibsonowi - z których każdy odgrywa po kilkanaście ról, na scenie towarzyszy bowiem pianista (Harlan Hodges) na żywo tworzący interpretacje muzyczne oraz specjalista od efektów specjalnych (Kelly Mattews), wytwarzający na oczach publiczności ścieżkę dźwiękową przy wykorzystaniu tzw. kuchni akustycznej. W tle wyświetlana jest natomiast każdorazowo projekcja złożona z ponad 1250 ręcznie malowanych, różnobarwnych, indywidualnych paneli komiksowych o wysokiej rozdzielczości (The Intergalactic Nemesis. Study Guide, 2016). Bill Graham tak ocenia ich walory artystyczne:

„szkice ołówkiem i atramentem zrobił Tim Doley, podczas gdy Paul Hanley oraz Lee Duhig dostarczyli umiejętność wypełniania ich kolorem i wszystko naprawdę eksploduje. To jest jak najlepsza sztuka pulp [fiction] jaką kiedykolwiek widzieliście, biorąc pod uwagę plamy żywych kolorów, które wzmacniają efekt. Trzeba podziwiać samą paletę kolorystyczną, a niektóre kadry są ciemniejsze i jaśniejsze, by dodatkowo wyeksponować atmosferę” (The Intergalactic Nemesis. Target Earth, 2015, s. 1).

Wprawdzie nie przypominają nasyceniem kolorystyki papierowych opowieści o Batmanie czy Iron Manie, ale ta wizualizacja jest „wystarczająca, by dostarczyć przedstawieniu materiałów ilustracyjnych, których potrzebuje, by być fascynujące” (Taurins, 2015, s. 3).

Dziś egzystencja „The Intergalactic Nemesis” jest więc bardzo różnorodna. Oprócz „komiksu radiowego” opowieść ta istnieje zarówno jako papierowa powieści graficzna, jak i wzbogacona obrazem prezentacja online (wykorzystująca podział ekranu), która jest efektem współpracy KLRU-TV i PBS Digital Studios. Można ją ponadto zobaczyć za pośrednictwem internetowych media playerów Xbox i Roku, a także na kanale Youtube, gdzie kolejne epizody udostępniano przez 17 tygodni. Odbiorcy mogą ją również „konsumować” pod postacią podcastu. Ta mnogość wcieleń sprawia, że pierwotnie kameralne słuchowisko - postrzegane przez samych jego twórców jako „ogromny eksperyment” (Eck, 2013, s. 1) z czasem zyskało status wielkiego hitu, który z zainteresowaniem omawiano zarówno na łamach czasopisma New York Times, jak i podczas popkulturowego talk show pt. „Conan O’Brien”, w trakcie którego główny prowadzący nie tylko rozmawiał z twórcami tego projektu, ale również sam odgrywał jego fragmenty (Hauman, 2012). 


\section{KONKLUZJE}

Analiza konkretnych przypadków współczesnych „komiksów radiowych” świadczy o tym, że tego typu hybrydyczne produkcje wprawdzie nie zagrażają klasycznym sztukom radiowym i papierowym opowieścią „z dymkiem”, ale są interesującym „zlepkiem”, który przełamuje tradycyjne granice narzucone przez dźwiękowe i wizualne media. Łącząc gatunki przypisane zwyczajowo do sfery sztuki wysokiej i przekazów popkulturowych, są interesującą innowacją kryjącą w sobie duży potencjał, bo otwierającą twórcom i odbiorcom nowe perspektywy.

Zastanawiając się, jaka przyszłość czeka „komiks radiowy”, wypada zgodzić się z konkluzją Janusza Łastowieckiego, który pisał:

„Jesteśmy gdzieś na początku, a powstające realizacje są dopiero forpocztą nowego gatunku. Propozycja może budzić niezrozumienie wśród najbardziej zachowawczych miłośników gatunku, którzy kształtowali się w słuchowiskowym azylu lat 60. Niemniej ten ikono-dźwiękowy sposób myślenia o słuchowisku ma szansę nawiązać kontakt z medialną rzeczywistością, od której słuchowisko jednak nie może się oddalić, by przetrwać” (Łastowiecki, 2015, s. 2).

\section{Bibliografia}

Alder, M. (2012). „Intergalactic Nemesis”: From Radio To Page To Stage. Pobrane z: http://www.npr.org/2012/01/12/145109197/intergalactic-nemesis-from-radio-to-page

Bauer, Z. (2009). Dziennikarstwo wobec nowych mediów. Historia. Teoria. Praktyka. Kraków: UNIVERSITAS.

Berry, R. (2013). Radio with pictures: Radio visualization in BBC national radio. The Radio Journal - International Studies in Broadcast \& Audio Media, 11(2), s. 169-184.

Copley, R. (2014). „Intergalactic Nemesis” a mashup of comic book and theater, lands at Norton Center. Pobrane z: http://kentucky.com/entertainment/performing-arts/ article44470131.html

Crook, T. (2015). International Radio Drama - Social, Economic and Literary Contexts. Pobrane z: http://www.irdp.co.uk/radiodrama.htm

Eck, M. (2013). From out of this world. Pobrane z: http://wwwtimesunion.com/living/ article/From-out-of-this-world-4373522.php

Fras, J. (2007). Podstawy identyfikacji i typologii wypowiedzi w mediach masowych. W: E. Kulczycki, M. Wendland (red.), Komunikologia. Teoria i praktyka komunikacji. Biblioteka Komunikacji Społecznej. TOM II (s. 13-29). Poznań: Wydawnictwo Naukowe WAM. 
Grand PiK 2015 - Małgorzata Żerwe (2015). Pobrane z: http://youtube.com/watch?v=CVYYEQAjpX4

Hampel, B. (2012). Hybrid of radio drama, comic books entertains in McCain Auditorium. Pobrane z: http://www.kstatecollegian.com/2012/09/24/hybrid-of-radio-drama-comic-book-ent

Hepp, A. (2006). Radio and Popular Culture in Germany: Radio Culture Between Comedy and „Event-isation”. W: A. Crisell (red.), More than a Music Box. Radio Cultures and Communities in a Multi-Media World (s. 189-212). New York/Oxford: Berghahn Books.

Herrera, B. (2015). The Intergalactic Nemesis: A Transmedia Multiverse Trilogy. Pobrane z: http://howlround.com/the-intergalactic-nemesis-a-transmedia-multiverse-trilogy-0 Jan Karski (2016). Pobrane z: http://audioteka.com/pl/audiobook/jan-karski

Jenkins, H. (2007). Kultura konwergencji. Zderzenie starych i nowych mediów. Warszawa: Wydawnictwa Akademickie i Profesjonalne.

Jędrzejewski, S. (2007). Radio. W: E. Chudziński (red.), Słownik wiedzy o mediach (s. 154-171). Warszawa: Wydawnictwo Szkolne PWN.

„Kafka Unchained”. Hörcomic von Malgorzata Zerwe und David Zane Mairowitz (2014). Pobrane z: http://www.deutschlandfunk.de/kafka-unchained-horcomic-von-malgorzatazerwe-und david.media.adc8cf69e28a3a38114664bf7a189053.pdf

Kopecka-Piech, K. (2011). Koncepcje konwergencji mediów. Studia medioznawcze, 3, s. $15-20$.

Łastowiecki, J. (2015). Radiowy komiks czyli gondola Aschenbacha i popijanie Wermuta w wersji audio. Pobrane z: http://www.e-teatr.pl/pl/artykuly/208318.html

Łukaszek, A. (2015). Gwiazdorska obsada w nowym serialu radiowym „Jan Karski”. Pobrane z: http://radioszczecin.pl/4,330246,gwiazdorska-obsada-w-nowym-serialuradiowym-ja

Łukaszek, A. (2016). „Jan Karski” w Radiu Szczecin. Słuchaj od poniedziałku. Pobrane z: http://radioszczecin.pl/1,332601,jan-karski-w-radiu-szczecin-sluchaj-od-poniedzialku.

Otten, L. (2011). The Intergalactic Nemesis: Live- Action Graphic Novel. Pobrane z: http:// source.wustl.edu/2011/11/the-intergalctic-nemesis-liveaction-graphic-novel/

Rajnerowicz, K. (2015). Geometria zdrady. Pobrane z: http://dwutygodnik.com/artykul/5699-geometria-zdrady.html

Ross, R. (2014). A Life Action Comic Book Brings Zygon to Life. Pobrane z: http://www. nytimes.com/2014/09/07/us/a-live-action-comic book-briings-zygone-to-life.html

Taurins, J. (2015). The Intergalactic Nemesis. Pobrane z: http://theatrepeople.com.au/ the-intergalactic-nemesis

The Intergalactic Nemesis. Study Guide. (2016). Pobrane z: http://artscenter.naz.edu/Plone/ documents/the-intergalactic-nemesis-target-earth-study-guide

The Intergalactic Nemesis. Target Earth. Coming Feb. 10 (2015). Pobrane z: http://miamioh. edu/news/top-stories/2015/02/pas-intergalactic.html

Thompson, M. (2006). BBC Creative Futre:Mark Thompson's speech in full. Pobrane z: http://www.theguardian.com/media/2006/apr/25/bbc.broadcasting

W radiowym komiksie (2013). Pobrane z: http://www.dziennikteatalny.pl/artykuly/w-radiowym-komiksie.html 
Zapis rozmowy Justyny Nowickiej z Kubą Woynarowskim sprzed publikacji komiksu (2013). Pobrane z: http://www.radiokrakow.pl/kultura/komiks-inspirowany-sluchowiskiem-nietoty/

Zrodzeni poza komiksem (2015). Pobrane z: http://lekturaobowiązkowa.pl/komiksy/ zrodzeni-poza-komiksem 